\title{
Late and Fatal Deterioration of an Intracerebral Hemorrhage Attributable to the Onset of a High Titer of Acquired Factor V Inhibitor
}

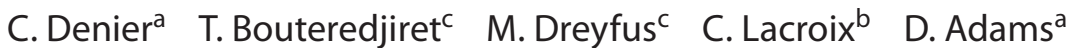 \\ Departments of a Neurology and ${ }^{\mathrm{b}}$ Neuropathology and ${ }^{\mathrm{c} H e m a t o l o g y}$ Laboratory, Bicêtre Hospital, \\ Le Kremlin-Bicêtre; Assistance Publique Hôpitaux de Paris, Université Paris-Sud 11, Paris, France
}

\begin{abstract}
Dear Sir,
Spontaneous intracerebral hemorrhages (ICH) are frequent and associated with high morbidity and mortality $[1,2]$. Classical risk factors for $\mathrm{ICH}$ are hypertension, age, male sex and high alcohol intake [1]. Secondary ICH worsening occurs in up to $20-40 \%$ of patients [2-5]. Progression of mass effect is mainly described at 2 time points: within the 2 first days associated with extension of the hematoma, and during the second and third weeks associated with progression of the edema [2-5]. We report herein a late clinical deterioration following ICH, due to the development of a severe acquired coagulation abnormality.
\end{abstract}

\section{Case Report}

A 75-year-old man was admitted to our hospital because of left hemiplegia. He had a previous history of hypertension that dated from many years; antihypertensive medications had been prescribed, but the patient was not compliant. He consumed alcohol to excess. Upon admission, examination showed that although somnolent, he could easily respond to simple orders; a left hemiplegia was present with an ipsilateral Babinski sign. His blood pressure was 230/110 mm Hg. A brain CT scan showed an ICH in the right basal ganglia inducing a slight midline shift, in association with diffuse leukoaraiosis. Initial hematological and biochemical values were normal, including coagulation tests. Fluid intake was reduced and intravenous antihypertensive medication was introduced (nicardipine) in association with omeprazole, polyvitamin and aminopenicillin for a pulmonary infection due to swallowing dysfunction. This ICH was considered as related to the untreated severe hypertension. Two weeks later, after an initial partial clinical recovery, marked neurological deterioration occurred, leading to coma associated with a right hemiparesis associated with the preexisting left hemiplegia. At the same time, gastrointestinal bleeding appeared. Blood pressure ranged between 150/70 and 170/90 mm Hg. Laboratory findings showed prolonged prothrombin time $(\mathrm{PT}<10 \%)$ and activated partial thromboplastin time (aPTT $>120 \mathrm{~s}$; control $35 \mathrm{~s}$ ), both normal on admission 14 days before. PT and aPTT were prolonged on a 1:1 mixture of patient and normal plasma, suggesting the presence of an acquired coagulation inhibitor. The factor $\mathrm{V}$ activity level was undetectable $(<3 \%)$, while the activity levels of the other clotting factors were within the normal range, as well as the fibrinogen level, thrombin time and platelet count. Fibrin degradation products were undetectable. These abnormalities were related to a specific factor $\mathrm{V}$ inhibitor titrating 13 Bethesda units. The patient died 4 days later without any coagulation improvement, despite high-dose intravenous immunoglobulin therapy. Complete autopsy was unremarkable apart from duodenal ulceration. There was no evidence of digestive cancer, central nervous system tumor or vascular malformation. Cerebral examination confirmed the presence of the right ICH in the basal ganglion region, spreading to the pons and associated with a massive and recent intraventricular bleeding. This expansion was attributed to secondary bleeding from the primary source secondary to the acquired coagulation abnormality. In our case, the acquired factor $\mathrm{V}$ inhibitor was attributed to aminopenicillin prescribed for a pulmonary infection prior to clinical deterioration (see below).

\section{Discussion}

Spontaneous ICH is a potentially disastrous event that may complicate acquired coagulation or hemostasis abnormalities, including clotting factor inhibitors. Most clotting factor inhibitors have been reported in hemophilia. They occur in about 5$20 \%$ of hemophiliacs, secondary to replacement therapy with factor VIII concentrates. Rarely, factor VIII inhibitors have been reported in nonhemophilic patients, occurring most often in the elderly,

\section{KARGER}

Fax +41 613061234

E-Mail karger@karger.ch

www.karger.com (c) 2008 S. Karger AG, Basel

0014-3022/08/0604-0206\$24.50/0

Accessible online at:

www.karger.com/ene
Dr. Christian Denier

Department of Neurology, Centre hospitalier de Bicêtre

78, rue du Général-Leclerc

FR-94275 Le Kremlin-Bicêtre (France)

Tel. +33 145212 618, Fax +33 145212 853, E-Mail christian.denier@bct.aphp.fr 
in patients with autoimmune disorders, and in women after delivery (with only a few hundred cases in the literature) [6]. More rarely, other autoantibodies, such as factor V inhibitors, have been reported.

Congenital severe factor $\mathrm{V}$ deficiency is a rare bleeding disorder; its incidence is about 1 in $10^{6}$ [7]. Acquired inhibitors to factor $V$ are also very infrequent: 105 cases have been reported between 1955 and 1997 [8]. More recently, Favaloro et al. [9] reported 14 new cases of acquired factor $\mathrm{V}$ deficiency in a multicentric investigation, with an estimated annual incidence in Australia of around 0.29 per million [9]. In $40 \%$ of the cases, acquired factor V inhibitors are not associated with any bleeding features, being detected in patients with an unexpected abnormal PT and/or aPTT [8-10]. Among symptomatic patients, an intracerebral bleeding site is very uncommon, occurring in $6 \%$ of cases, the other sites being mostly caused by surgical wounds, hematuria, gastrointestinal bleeding and epistaxis [8].

Diseases and conditions associated with factor $\mathrm{V}$ inhibitors are numerous. Up to $50 \%$ of factor $\mathrm{V}$ inhibitors developed after exposure of patients to topical hemostatic agents containing bovine $\alpha$-thrombin, used during cardiovascular, orthopedic and neurosurgical procedures. Bovine thrombin preparations contain trace amounts of bovine factor $\mathrm{V}$ that favors the development of antibodies cross-reacting with human factor V. The availability of human hemostatic preparations should lead to a dramatic decrease in the occurrence of this pathology. However, it was not the case in the recent report of Favaloro et al. [9]. Factor V inhibitors have also been reported in association with other conditions: transfusion of blood components, $\beta$-lactam antibiotic administration and/or surgery $[8,10]$. They have also been reported in association with autoimmune disorders such as Sjögren's syndrome, celiac disease, bullous pemphigoid, malignant diseases such as myeloma, colic, pancreatic or central nervous system neoplasia and anaplastic carcinoma, acquired immunodeficiency syndrome or tuberculosis $[8,10]$. In $18 \%$ of the cases, no underlying disease, associated condition or exposure to treatment could be demonstrat- ed, and they are considered as 'idiopathic factor V inhibitor' [8]. Acquired factor V inhibitor was attributed in our case to aminopenicillin antibiotics prescribed over the course of 2 weeks for pulmonary infection prior to clinical deterioration.

Treatment of acute bleeding episodes in patients with factor $\mathrm{V}$ inhibitors is difficult, as no factor $\mathrm{V}$ concentrates are available for replacement therapy. The main objectives are to control the hemorrhagic event, and to decrease the antibody titer. When possible, the treatment of the underlying pathology often leads to the disappearance of the factor $\mathrm{V}$ inhibitor [8]. Because randomized studies are lacking due to the rare occurrence of factor $\mathrm{V}$ inhibition, it is almost impossible to recommend a treatment modality based on scientific evidence. Fresh frozen plasma is frequently given, but often ineffectively. In contrast, the administration of activated prothrombin complex concentrates or transfusion of platelet concentrates, which contain $20 \%$ of the circulating factor $\mathrm{V}$, can be effective $[8,10]$. Treatment with recombinant factor VIIa has demonstrated its tolerance and possible efficiency in spontaneous ICH [11]. However, it has not been used to date in cases of bleeding due to factor $\mathrm{V}$ inhibitors. Approaches to decrease the factor $\mathrm{V}$ inhibitor antibody titer include steroids, cytotoxic therapy, intravenous immunoglobulins and plasmapheresis [8-10]. In patients with severe life-threatening bleeding, Knobl and Lechner [8] recommend the association of iterative plasmapheresis together with supplementation with fresh frozen plasma, with or without platelet concentrates, and immunosuppressive treatment (steroids plus cyclophosphamide or azathioprine). In our case, immunoglobulin infusions were clinically and biologically unsuccessful, in contrast to other reports [12].

This iatrogenic complication must be known and appears to be comparable to the development of drug-induced thrombopenia related to the application of heparin. Our observations suggest that coagulation tests should be systematically performed in the case of secondary deterioration of $\mathrm{ICH}$ due to new bleeding and/ or expansion of hematoma, even if they were initially normal.

\section{Acknowledgment}

The authors thank Michael Dubow for editing assistance.

\section{References}

-1 Ariesen MJ, Claus SP, Rinkel GJ, Algra A: Risk factors for intracerebral hemorrhage in the general population: a systematic review. Stroke 2003;34:2060-2065.

- 2 Qureshi AI, Tuhrim S, Broderick JP, Batjer $\mathrm{HH}$, Hondo H, Hanley DF: Spontaneous intracerebral hemorrhage. N Engl J Med 2001; 344:1450-1460.

- 3 Zazulia AR, Diringer MN, Derdeyn CP, Powers WJ: Progression of mass effect after intracerebral hemorrhage. Stroke 1999;30: 1167-1173.

-4 Brott T, Broderick J, Kothari R, et al: Early hemorrhage growth in patients with intracerebral hemorrhage. Stroke 1997;28:1-5.

5 Leira R, Davalos A, Silva Y, et al: Early neurologic deterioration in intracerebral hemorrhage: predictors and associated factors. Neurology 2004;63:461-467.

6 Zakarija A, Green D: Acquired hemophilia: diagnosis and management. Curr Hematol Rep 2002;1:27-33.

7 Ajzner E, Balogh I, Haramura G, et al: Antifactor $\mathrm{V}$ auto-antibody in the plasma and platelets of a patient with repeated gastrointestinal bleeding. J Thromb Haemost 2003; 1 : 943-949.

8 Knobl P, Lechner K: Acquired factor V inhibitors. Baillières Clin Haematol 1998;11: 305-308.

-9 Favaloro EJ, Posen J, Ramakrishna R, et al: Factor $\mathrm{V}$ inhibitors: rare or not so uncommon? A multi-laboratory investigation. Blood Coagul Fibrinolysis 2004;8:637-647.

10 Ortel TL: Clinical and laboratory manifestations of anti-factor V antibodies. J Lab Clin Med 1999;133:326-334.

11 Mayer SA, Brun NC, Begtrup K, et al: Recombinant activated factor VII for acute intracerebral hemorrhage. N Engl J Med 2005; 352:777-785

12 de Raucourt E, Barbier C, Sinda P, Dib M, Peltier JY, Ternisien C: High-dose intravenous immunoglobulin treatment in two patients with acquired factor V inhibitors. Am J Hematol 2003;74:187-190. 